(C) 2021, The Authors. Published by Elsevier Inc. and Fass Inc. on behalf of the American Dairy Science Association ${ }^{\circledR}$. This is an open access article under the CC BY-NC-ND license (http://creativecommons.org/licenses/by-nc-nd/4.0/).

\title{
Including milk production, conformation, and functional traits in multivariate models for genetic evaluation of lameness
}

\author{
M. Khansefid, ${ }^{1 *} \odot$ M. Haile-Mariam,${ }^{1} \odot$ and J. E. Pryce ${ }^{1,2} \odot$ \\ ${ }^{1}$ Agriculture Victoria Research, AgriBio, Centre for AgriBioscience, Bundoora, Victoria 3083, Australia \\ ${ }^{2}$ School of Applied Systems Biology, La Trobe University, Bundoora, Victoria 3083, Australia
}

\begin{abstract}
Lameness is a serious health and welfare issue that can negatively affect the economic performance of cows, especially on pasture-based dairy farms. However, most genetic predictions (GP) of lameness have low accuracy because lameness data are often incomplete as data are collected voluntarily by farmers in countries such as Australia. The objective of this study was to find routinely measured traits that are correlated with lameness and use them in multivariate evaluation models to improve the accuracy of GP for lameness. We used health events and treatments associated with lameness recorded by Australian farmers from 2002 to early 2019. The lameness incidence rates in Holstein and Jersey cows were $3.3 \%$ and $4.6 \%$, respectively. We analyzed the records of 36 other traits (milk production, conformation, fertility, and survival traits) to estimate genetic correlations with lameness. The estimated heritability \pm standard error (and repeatability \pm standard error) for lameness in both Holstein and Jersey breeds were very low: $0.007 \pm 0.002$ (and $0.029 \pm 0.002$ ) and 0.005 \pm 0.003 (and $0.027 \pm 0.006$ ), respectively, in univariate sire models. For the GP models, we tested including measurements of overall type to prediction models for Holsteins, stature and body length for Jersey, and milk yield and fertility traits for both breeds. The average accuracy of GP, calculated from prediction error variances, were 0.38 and 0.24 for Holstein and Jersey sires, respectively, when estimated using univariate sire models and both increased to 0.43 using multivariate sire models. In conclusion, we found that the accuracy of GP for lameness could be improved by including genetically correlated traits in a multivariate model. However, to further improve the accuracy of predictions of lameness, precise identification and recording incidences of hoof or leg disorder, or large-scale recording of locomotion and claw scores by trained personnel should be considered.
\end{abstract}

Received December 22, 2020.

Accepted June 3, 2021.

*Corresponding author: majid.khansefid@agriculture.vic.gov.au
Key words: dairy cow, lameness, conformation trait, functional trait, multivariate model

\section{INTRODUCTION}

Selective breeding for better cow health is one strategy to improve dairy farm profitability, by reducing the costs associated with veterinary treatments and management, involuntary culling, and the potential detrimental effects on economic traits (Abdelsayed et al., 2017). Lameness, mastitis, and fertility-related issues are major health problems in dairy cattle (Bruijnis et al., 2010). Lameness is also a serious animal welfare concern and is associated with reduced milk production in addition to metabolic disorders, reproductive problems and the reason for up to $15 \%$ of all culls in dairy farms (Green et al., 2002; Buch et al., 2011; Huxley, 2013).

The reported prevalence of lameness in different studies varies considerably, probably because of the difficulty in case detection, which is especially true of subclinical cases (i.e., those that do not cause distinctive posture or locomotion abnormality) and whether these are considered to be lameness records (Green et al., 2002). Moreover, there is a large variation in the frequency of lameness across different herds and between countries, especially those that have voluntarily compared with those where mandatory recording programs of health events are in place (Rouha-Mülleder et al., 2009; Heringstad et al., 2018; Bonfatti et al., 2020). Consequently, the lameness incidence rate in different studies was reported to vary between $2 \%$ and $70 \%$ (van der Waaij et al., 2005; Abdelsayed et al., 2017). Beggs et al. (2019) reported that in Australian dairy farms, whereas all severely lame cows could be detected by farmers, only about $25 \%$ of unsound and moderately lame cows that walk unevenly or favoring one leg could be detected.

Difficulty in mobility can be caused by infections (such as digital or interdigital dermatitis and footrot) or noninfectious diseases associated with unsuitable housing and flooring conditions (such as sole or toe ulcers and abscesses) and any disorders associated with 
poor conformation or defects of lower limbs (such as scissor/screw claw and defective foot/heel conformation; Cha et al., 2010; O'Connor et al., 2020a). Furthermore, lameness can also occur due to accidents (dislocated hip, and feet or upper leg injuries), metabolic or nutritional disorders (such as milk fever and rumen acidosis), and other health problems (such as arthritis and calving paralysis; Lawson et al., 2004; Bruijnis et al., 2010). Hence, lameness is a multifactorial disease that has as its most obvious clinical sign, impaired or painful mobility (Van Nuffel et al., 2015). The diversity of reasons for lameness, along with different types of treatments, makes it difficult to calculate the overall economic impact and genetic component of this trait.

The economic impact of lameness mainly depends on its underlying reason, type (subclinical or clinical), severity, lactation stage, and type and duration of treatment (Bruijnis et al., 2010; Cha et al., 2010). Bruijnis et al. (2010) reported that the average economic loss for subclinical and clinical cases in Dutch herds was $\$ 18$ and $\$ 95$, respectively. The loss per clinical lameness case was estimated to be $\$ 121$ for footrot, $\$ 133$ for digital dermatitis, and $\$ 216$ for sole ulcer by Cha et al. (2010) in the United States. Moreover, the cost per case in cows with very high milk yield and open cows (i.e., nonpregnant) was found to be higher than average lameness costs in the herd (Ettema and Østergaard, 2006; Cha et al., 2010).

Given the complexities of lameness and the practical limitations in detection and recording of all cases, the estimated heritability is generally low and ranged between 0.02 to 0.10 in the studies reviewed by Heringstad et al. (2018). Accordingly, the genetic predictions (GP) for lameness, locomotion, and claw scores have low to modest accuracies. However, previous studies found that the inclusion of auxiliary, or predictor traits, which were correlated with health traits, could be useful to improve the accuracy of predictions (Haile-Mariam and Goddard, 2010). It has been reported that including conformation traits and hoof trimming data, and combining multiple locomotion-related measurements, such as locomotion and claw scores, could improve the accuracy of GP for leg and claw health traits (Laursen et al., 2009; van der Linde et al., 2010).

The objectives of this research were to (1) calculate phenotypic and genetic correlations between lameness and 36 routinely measured traits on Australian farms including 3 milk production (305-d lactation milk, fat, and protein yields), 31 conformation, calving interval (fertility), and survival traits and (2) include the traits that were correlated with lameness as predictor traits in multivariate evaluation models to improve the accuracy of GP for lameness. For further information about the conformation traits used in this study, visit https:/
/datagene.com.au/sites/default/files/Upload\%20Files/ 02\%20Type\%20ABVs\%20explained\%20Mar\%202020 -0.pdf.

\section{MATERIALS AND METHODS}

\section{Data}

Voluntarily collected health data recorded by farmers and other official herd record data used in this study were accessed from DataGene Pty Ltd. (Melbourne, Australia). The health incidences were extracted from January 2002 to the end of March 2019. In this research we included treatments (antibiotics and antiinflammatory drugs for hoof and leg) and health events (footrot, abscess, paralysis at calving, upper leg problems, downer cow, disclosed hip, and arthritis) associated with moving difficulties. The lameness incidences might not be recorded for some farms, or herd-years, because collecting health data is not mandatory in Australia. Hence, the cows were considered healthy (i.e., nonlame), only if there was at least one recorded case of lameness within that contemporary group (i.e., herdyear-season group). In total, we used lameness data (lame and nonlame) of 163,891 Holstein and 19,990 Jersey cows in our study. The majority of the repeated records of lameness for each cow per lactation were less than $30 \mathrm{~d}$ apart and thus it was difficult to distinguish a new case of lameness from the repeated recording of a single case. Therefore, we considered multiple lameness cases per lactation as an indication of the same disease and only kept the first record which showed the onset of the lameness case.

The pedigree-based breed composition of the lame cows and their healthy herd counterparts were used to extract the pure Holstein and pure Jersey cows. Note, we studied lameness in each of these breeds separately and excluded crossbred cows because they were too few. For each group of purebred cows, the main pedigree file was trimmed by removing the individuals not genetically connected to the lame and nonlame cows. The number of animals in the trimmed pedigree (and pedigree depth shown within parentheses) were 728,580 (21 generations) and 88,338 (22 generations) for Holsteins and Jerseys, respectively. The conformation and milk production records as well as fertility and survival trait deviations (TD; i.e., phenotypes pre-corrected for fixed effects, such as herd-year-season and so on) of the individuals in the trimmed pedigree files were used in our study. To remove potential errors from the data, we checked various details following similar rules as Abdelsayed et al. (2017); for example, age at calving and completed lactation length had to be 18 to 220 mo and 9 to 15 mo, respectively. 


\section{Analyses}

All of the analyses were conducted separately for Holstein and Jersey breeds using ASReml (Gilmour et al., 2015).

Univariate Models. Lameness recorded as a binary trait (healthy or lame) in our data set was analyzed using ordinary linear sire and animal models, as well as binomial threshold (i.e., binary logistic regression) sire and animal models. The general model used was

$$
\mathbf{y}=\mathbf{X b}+\mathbf{Z u}+\mathbf{W c}+\mathbf{e}
$$

where $\mathbf{y}$ is the vector of phenotypic records ( 0 for nonlame and 1 for lame cows); $\mathbf{b}$ is the vector of fixed effects of contemporary group or herd-year-season (calving season: autumn calving $=$ January-June and spring calving $=$ July-December $)$ and age at calving fitted as covariate; $\mathbf{u}$ is the vector of random polygenic effects or EBV; $\mathbf{c}$ is the vector of random cow permanent environment effects; $\mathbf{e}$ is the vector of random residual effects; and $\mathbf{X}, \mathbf{Z}$, and $\mathbf{W}$ are design matrices relating observations to the corresponding effects. We dropped month of calving and parity from our initial model because their effects were not significant and probably were absorbed in contemporary groups and age at calving.

The assumed distributions for the aforementioned random effects in linear models were

$$
\left(\begin{array}{l}
\mathbf{u} \\
\mathbf{c} \\
\mathbf{e}
\end{array}\right) \sim N\left(0, \quad\left(\begin{array}{c}
\mathbf{A} \sigma_{u}^{2} \\
\mathbf{I} \sigma_{c}^{2} \\
\mathbf{I} \sigma_{e}^{2}
\end{array}\right)\right),
$$

where $\sigma_{u}^{2}$ in animal (and sire) model corresponds to the animal (and the sire) genetic variance; $\sigma_{c}^{2}$ and $\sigma_{e}^{2}$ are cow permanent environment and residual variances, respectively; $\mathbf{A}$ is the additive relationship matrix calculated from pedigree information; and $\mathbf{I}$ is the identity matrix.

For threshold analysis, the same sire and animal models were fitted with binomial distribution and a LOGIT link function in ASReml, which implies an underlying logistic distribution with error variance $\pi^{2} / 3$.

Bivariate Models. We ran a series of bivariate sire models to find the traits genetically correlated with lameness. The models include lameness as trait 1 and one of the estimated 305-d production (milk, fat, and protein yields) calculated from the test day records, conformation traits, or fertility TD as trait 2 . The general model used was

$$
\begin{aligned}
& \left(\begin{array}{l}
\mathbf{y}_{1} \\
\mathbf{y}_{2}
\end{array}\right)= \\
& \left(\begin{array}{cc}
\mathbf{X}_{1} & 0 \\
0 & \mathbf{X}_{2}
\end{array}\right)\left(\begin{array}{l}
\mathbf{b}_{1} \\
\mathbf{b}_{2}
\end{array}\right)+\left(\begin{array}{cc}
\mathbf{Z}_{1} & 0 \\
0 & \mathbf{Z}_{2}
\end{array}\right)\left(\begin{array}{l}
\mathbf{u}_{1} \\
\mathbf{u}_{2}
\end{array}\right)+\left(\begin{array}{cc}
\mathbf{W}_{1} & 0 \\
0 & \mathbf{W}_{2}
\end{array}\right)\left(\begin{array}{l}
\mathbf{c}_{1} \\
\mathbf{c}_{2}
\end{array}\right)+\left(\begin{array}{l}
\mathbf{e}_{1} \\
\mathbf{e}_{2}
\end{array}\right)
\end{aligned}
$$

where the model terms for trait 1 (lameness) are similar to the previously described univariate sire model; $\mathbf{y}_{2}$ is the vector of phenotypic records for trait $2 ; \mathbf{b}_{2}$ is the vector of fixed effects [for 305-d lactation milk, fat, and protein yield: herd-year-season, parity, and age at calving fitted as covariate; for conformation traits: herd-year-classifier and DIM and age at classification date fitted as covariate; for fertility TD: the phenotypes were already adjusted by DataGene for all known fixed effects including herd-year-season, parity, and month of calving, as described by Haile-Mariam et al. (2015)]; $\mathbf{u}_{2}$ is the vector of random genetic effects, or EBV for trait $2 ; \mathbf{c}_{2}$ is the vector of random cow permanent environment effects for milk production traits as each cow could have multiple lactation records; and $\mathbf{e}_{2}$ is the vector of random residual effects. $\mathbf{X}_{2}, \mathbf{Z}_{2}$, and $\mathbf{W}_{2}$ are design matrices for $\mathbf{b}_{2}, \mathbf{u}_{2}$, and $\mathbf{c}_{2}$, respectively. The random effects in the model were assumed to follow

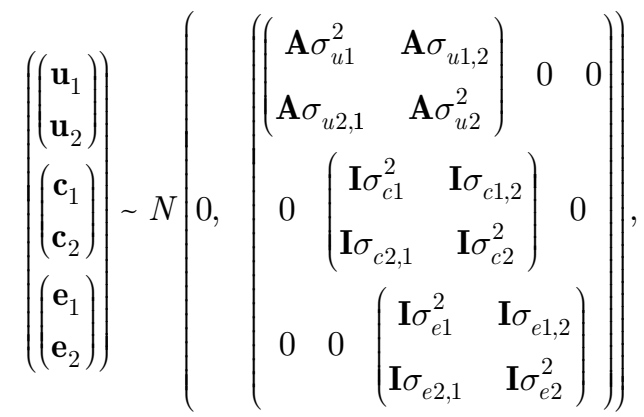

where A, I, and variances for trait 1 (lameness), are similar to the previously described univariate sire model; $\sigma_{u 2}^{2}, \sigma_{c 2}^{2}$, and $\sigma_{e 2}^{2}$ are genetic, cow permanent environment (for milk production traits), and residual variances for trait 2 , respectively; and $\sigma_{\mathrm{u} 1,2}, \sigma_{\mathrm{c} 1,2}$, and $\sigma_{\mathrm{e} 1,2}$ are genetic, cow permanent environment, and residual covariances between trait 1 and 2, respectively.

We also ran some bivariate sire models, this time between the traits genetically correlated with lameness to be able to use the estimated variances and covariances as priors for our multivariate models for lameness GP.

Multivariate Models. Based on the results from the bivariate analyses, we added the traits genetically correlated with lameness, one at the time, to the multivariate model. This was anticipated to help the model converge through using the re-estimated variance com- 
ponents in the previous model as priors in the subsequent model. However, when fitting many traits, such as composite overall type, rump, and mammary system traits and fertility, the model convergence could not be achieved. Moreover, including so many predictor traits, some of which had low phenotypic and genetic correlations with lameness in the multivariate models, could cause an overprediction of accuracy (Sales and Hill, 1976). Hence, in the multivariate models, we avoided including predictor traits highly correlated with each other, such as type traits associated with mammary system and milk yield in Holsteins and rump traits and fertility TD in Jerseys. In the final multivariate models, we fitted 4 traits for Holsteins (lameness, milk yield, composite overall type, and fertility TD) and 5 traits for Jerseys (lameness, milk yield, stature, body length, and fertility TD). Although the correlation between 305-d milk yield and fertility TD was high, both of them were included in the models because some cows had only milk yield or fertility records. The general model and the assumed (co)variance distributions for random effects were

$$
\begin{aligned}
& \left(\begin{array}{c}
\mathbf{y}_{1} \\
\vdots \\
\mathbf{y}_{n}
\end{array}\right)=\left(\begin{array}{ccc}
\mathbf{X}_{1} & \cdots & 0 \\
\vdots & \ddots & \vdots \\
0 & \cdots & \mathbf{X}_{n}
\end{array}\right)\left(\begin{array}{c}
\mathbf{b}_{1} \\
\vdots \\
\mathbf{b}_{n}
\end{array}\right)+\left(\begin{array}{ccc}
\mathbf{z}_{1} & \cdots & 0 \\
\vdots & \ddots & \vdots \\
0 & \cdots & \mathbf{z}_{n}
\end{array}\right)\left(\begin{array}{c}
\mathbf{u}_{1} \\
\vdots \\
\mathbf{u}_{n}
\end{array}\right) \\
& +\left(\begin{array}{ccc}
\mathbf{w}_{1} & \cdots & 0 \\
\vdots & \ddots & \vdots \\
0 & \cdots & \mathbf{w}_{n}
\end{array}\right)\left(\begin{array}{c}
\mathbf{c}_{1} \\
\vdots \\
\mathbf{c}_{n}
\end{array}\right)+\left(\begin{array}{c}
\mathbf{e}_{1} \\
\vdots \\
\mathbf{e}_{n}
\end{array}\right),
\end{aligned}
$$

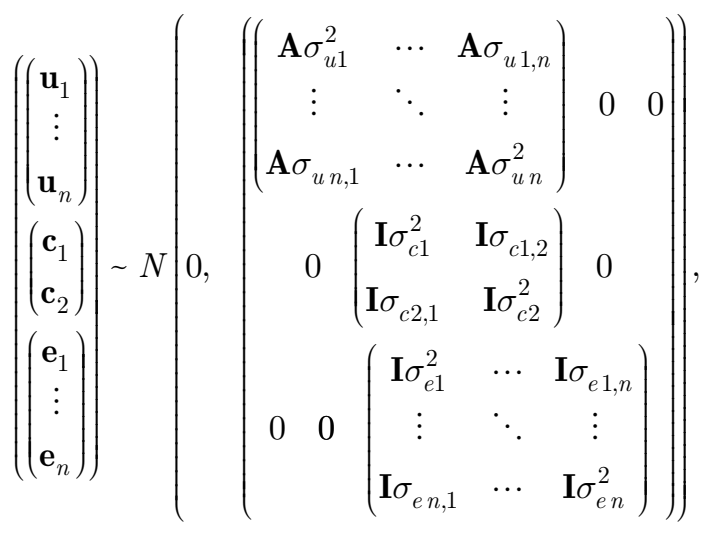

where the model terms for trait $n$ ( 1 to 4 for Holstein and 1 to 5 for Jersey) are similar to the previously described models. As lameness and milk yield were the only traits with multiple records per cow, the cow permanent environment effects are shown only for 2 traits in the (co)variance structure.

\section{Accuracy of Prediction Models}

The accuracy of GP for lameness was calculated as

$$
\text { accuracy }=\sqrt{1-\frac{\mathrm{PEV}_{i}}{\sigma_{u}^{2}}},
$$

where $\mathrm{PEV}_{i}$ is the prediction error variance (squared error of the $\mathrm{EBV}_{i}$ ) for animal $i$ in the pedigree and $\sigma_{u}^{2}$ is the estimated genetic variance in the prediction model.

The accuracies for Holstein and Jersey breeds were reported separately for 3 group of animals: (A) cows: the lame cows and their nonlame contemporaries, (B) sires: the sires of the cows in group $A$, and $(\mathrm{C})$ relatives: the relatives, other than sires, of the cows in group A. Further, the accuracy of lameness GP for the sires with different number of daughter records were also reported in 5 groups (sires with $<10,10-49,50-99,100-499$, and $\geq 500$ daughter records).

\section{RESULTS}

\section{Lameness Incidence Rate}

According to the health events and treatments that were recorded from January 2002 to the end of March 2019, antibiotic use was the most commonly recorded treatment for lameness, and footrot and feet abscess were the main reasons underlying lameness (Figure $1)$. The distribution of lameness cases across months between 2002 to 2018 showed that the incidence rate of lameness was higher in winter and early spring in Australia (Figure 2), which also aligned with the spring calving season (Figure 3). The distribution of lameness incidences in months after calving showed that about $40 \%$ of the first lameness cases were recorded in early lactation (Figure 4).

There were multiple lameness incidence records per lactation for about $15 \%$ of the cows (about $10 \%$ occurred within $30 \mathrm{~d}$ each other). Keeping just the first occurrence of lameness per lactation and their healthy contemporaries, we ended up with 163,891 Holsteins (306,483 records: 10,037 lame and 296,446 nonlame) and 19,990 Jersey cows (43,348 records: 1,974 lame and 41,374 nonlame). Consequently, the average ( \pm SD) number of healthy and lame records per cow was 1.9 \pm 1.2 for Holstein and $2.2 \pm 1.6$ for Jersey breed. The lameness incidence rate in Holstein and Jersey breeds were $3.3 \%$ and $4.6 \%$, respectively. 


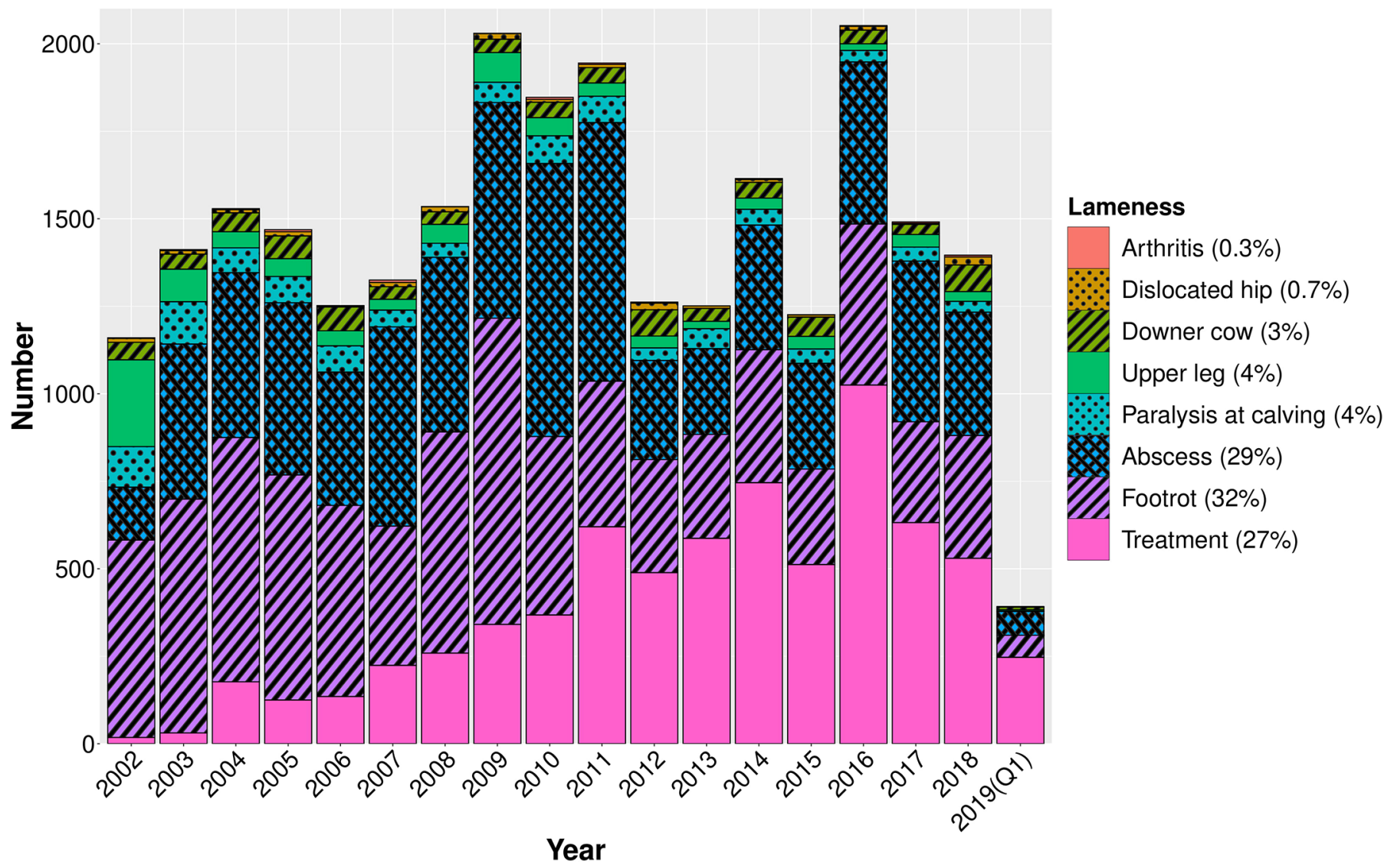

Figure 1. Distribution of recorded health events and treatments associated with lameness by Australian farmers from 2002 to the end of March 2019. Almost all cases related to lameness treatment were antibiotic application and the majority of lameness health events were related to footrot $(32 \%)$ and feet abscess $(29 \%)$. Q1 = quarter 1 .

\section{Heritability and Repeatability of Lameness}

The estimated heritability $\left(\mathrm{h}^{2}\right)$ and repeatability $\left(\mathbf{r}^{2}\right)$ of lameness in Holstein and Jersey breeds from different univariate models are shown in Table 1 . The estimated $\mathrm{h}^{2}$ and $\mathrm{r}^{2}$ were higher in binomial threshold compared with ordinary linear models, but there were very few differences between estimates based on sire and animal models. In multivariate sire models compared with univariate sire models, the $\mathrm{h}^{2}$ in Holsteins slightly increased from $0.007 \pm 0.002$ to $0.008 \pm 0.002$ but the $\mathrm{r}^{2}$ did not change $(0.029 \pm 0.002)$, and the $h^{2}\left(\right.$ and $\left.r^{2}\right)$ in Jerseys increased from $0.005 \pm 0.003$ to $0.008 \pm 0.004$ (and $0.027 \pm 0.006$ to $0.029 \pm 0.006$ ).

\section{Correlation Between Lameness and Other Traits}

The estimated phenotypic $\left(\mathbf{r}_{\mathrm{p}}\right)$, cow permanent environment $\left(\mathbf{r}_{\mathrm{pe}}\right)$, and genetic $\left(\mathbf{r}_{\mathrm{g}}\right)$ correlation coefficients between lameness and 3 milk production and 31 conformation traits, and fertility and survival TD are reported in Table 2. The estimated $h^{2}$ and $r^{2}$ for these traits had larger SE in Jerseys compared with Holsteins because there were fewer records in the Jersey breed data set (Table 2).

Generally, there were moderate positive (unfavorable) $r_{p}$ and $r_{g}$ between lameness and milk production traits in both Holstein and Jersey breeds. For the linear "mammary system" type traits (udder depth, udder texture, median suspensory, fore attachment, front teat placement, rear attachment height, rear attachment width, rear teat placement, teat length, and front end height), the $r_{p}$ were negligible. However, there were negative (favorable) correlations between lameness and aggregated mammary system traits (i.e., composite mammary system) in Holstein $\left(\mathrm{r}_{\mathrm{p}}=-0.013 \pm 0.007\right.$; $\left.\mathrm{r}_{\mathrm{g}}=-0.167 \pm 0.092\right)$ and in Jersey $\left(\mathrm{r}_{\mathrm{p}}=-0.074 \pm\right.$ $0.029)$. The $r_{g}$ between lameness and udder texture, median suspensory, and fore attachment in Holstein were $-0.111 \pm 0.093,-0.114 \pm 0.093$, and $-0.134 \pm 0.091$, respectively. The estimated correlation coefficients in Jersey for type traits were stronger but often had larger $\mathrm{SE}$; for example, $\mathrm{r}_{\mathrm{g}}$ for fore attachment and rear teat 
placement were $0.508 \pm 0.242$ and $0.542 \pm 0.229$, respectively (Table 2 ).

For the linear and composite "feet and legs" type traits (foot angle, heel depth, rear legs-rear view, and rear legs-side view), the $r_{p}$ and $r_{g}$ were small with large $\mathrm{SE}$ that were often not consistent across breeds. For example, lameness was genetically correlated with rear legs-rear view in Holstein $(0.019 \pm 0.104)$ and in Jersey $(0.383 \pm 0.223)$ breeds, but the estimated phenotypic correlation was negative in Holstein $(-0.010 \pm 0.007)$ and positive in Jersey $(0.144 \pm 0.029)$.

In Jerseys, the linear and composite "rump" type traits (pin set, pin width, rump length, and loin strength), were correlated with lameness. There were unfavorable $\mathrm{r}_{\mathrm{g}}$ between lameness and pin set $(0.447 \pm$ $0.231)$, rump length $(0.697 \pm 0.191)$, and loin strength $(0.462 \pm 0.217)$. Furthermore, of the linear "dairy strength" traits (stature, muzzle width, chest width, body depth, angularity, and body length), the ones associated with body size were also correlated with incidences of lameness in the Jersey breed. Hence, lame- ness was genetically correlated with stature $(0.458 \pm$ $0.211)$ and body length $(0.630 \pm 0.179)$. Additionally, although the $r_{p}$ between lameness and BCS was small, the $r_{\mathrm{o}}$ in Holstein and in Jersey were $0.111 \pm 0.106$ and $0.423 \pm 0.417$, respectively.

In Holsteins, there was a favorable correlation between lameness and composite "overall type" trait $\left(\mathrm{r}_{\mathrm{p}}\right.$ $=-0.015 \pm 0.007$ and $\left.\mathrm{r}_{\mathrm{g}}=-0.180 \pm 0.093\right)$. However, in Jersey, the estimated $r_{p}(-0.074 \pm 0.029)$ and $r_{g}$ $(0.250 \pm 0.277)$ were in the opposite direction and had large SE.

Lameness was consistently correlated with poor fertility (i.e., longer calving interval) in Holstein $\left(\mathrm{r}_{\mathrm{p}}\right.$ $\left.=0.019 \pm 0.003 ; \mathrm{r}_{\mathrm{g}}=0.162 \pm 0.082\right)$ and Jersey $\left(\mathrm{r}_{\mathrm{p}}\right.$ $\left.=0.020 \pm 0.010 ; r_{\mathrm{g}}=0.265 \pm 0.252\right)$. Lameness was also correlated with reduced survival in Holstein $\left(\mathrm{r}_{\mathrm{p}}=\right.$ $\left.-0.023 \pm 0.003 ; r_{g}=-0.018 \pm 0.085\right)$ and Jersey $\left(r_{p}\right.$ $\left.=-0.004 \pm 0.009 ; r_{g}=-0.012 \pm 0.224\right)$, though the estimates were associated with large SE.

The estimated $r_{p}$ and $r_{g}$ between the traits in multivariate models in Holstein (and Jersey) are shown in

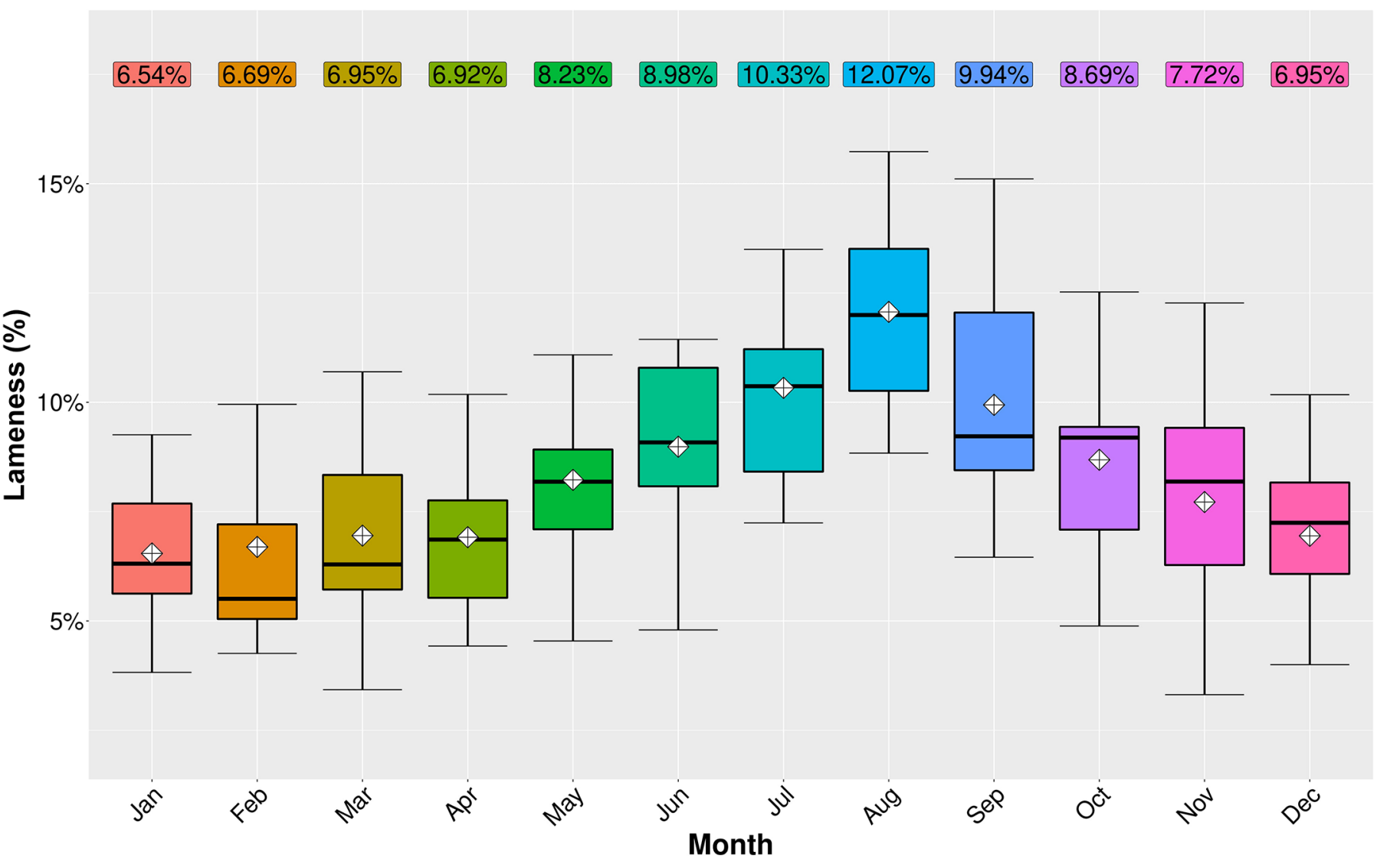

Figure 2. Distribution of lameness cases by month using data from 2002 to 2018. A higher proportion of lameness incidences occurred in July (10.33\%), August (12.07\%), and September (9.94\%). In the boxplots, the boxes show the middle 50\% or interquartile range (i.e., the range between the first and third quartiles), the whiskers represent the data outside the middle $50 \%$ (i.e., the lower and upper $25 \%$, outlier exclusive), the diamond marks show the average, and the horizontal lines in the boxes denote the median of the data. 


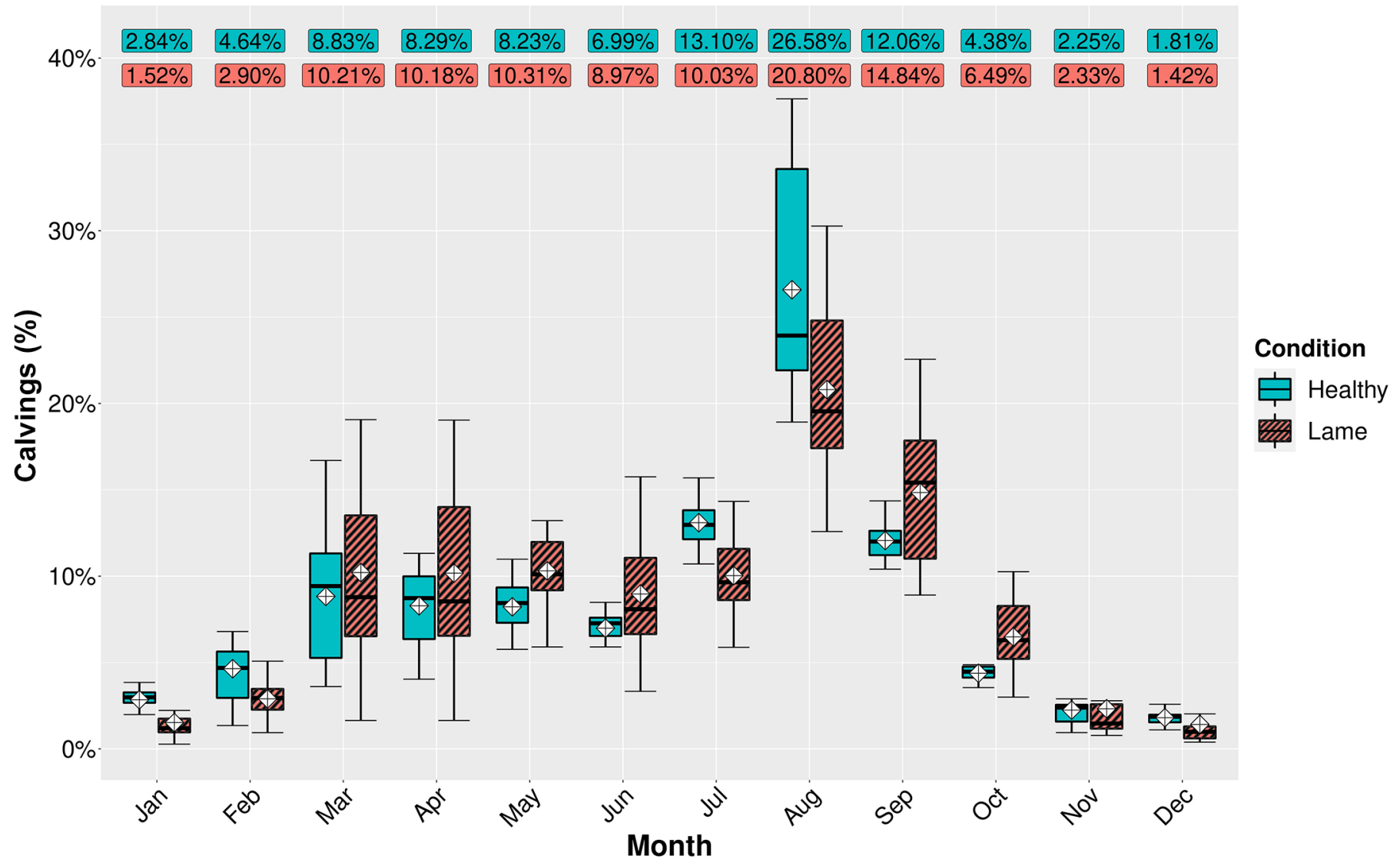

Figure 3. Distribution of calvings of cows with lameness health records and their healthy cohorts across months during 2001 to 2018 . The proportion of calvings in August was the highest for both groups of healthy (26.58\%) and lame (28.80\%) cows. In the boxplots, the boxes show the middle $50 \%$ or interquartile range (i.e., the range between the first and third quartiles), the whiskers represent the data outside the middle $50 \%$ (i.e., the lower and upper $25 \%$, outlier exclusive), the diamond marks show the average, and the horizontal lines in the boxes denote the median of the data.

Table 3 (and Table 4). The estimated $\mathrm{h}^{2}$ of the traits are also shown in the tables. The estimated $\mathrm{r}^{2}$ for lameness and milk yield and the $\mathrm{r}_{\mathrm{pe}}$ between them in Holstein (and Jersey) were $0.029 \pm 0.002,0.458 \pm 0.004$ and $0.055 \pm 0.022$ (and $0.029 \pm 0.006,0.541 \pm 0.013$, and $0.028 \pm 0.052)$, respectively.

\section{Genetic Prediction of Lameness}

The Pearson correlation coefficients between EBV from the binomial threshold models and their equivalent linear models were very high $(\mathrm{r}>0.99)$, likewise the correlation between the accuracy of predictions in these models $(\mathrm{r}>0.98)$. Additionally, the parameter convergence criteria of bivariate and multivariate ordinary linear models were quicker and easier to achieve (i.e., more flexible to the priors) compared with threshold models in ASReml. Hence, the accuracy of GP for lameness was reported just for ordinary linear models in this paper.
The average and the distribution of the accuracy of lameness predictions in Holstein and Jersey breeds using univariate and multivariate sire or animal models are shown in Figure 5. We could not get the GP for multivariate animal model in Holsteins due to convergence and memory allocation problems in ASReml for solving the massive number of equations. Generally, the accuracy of GP was higher in multivariate compared with univariate models and improved further by fitting animal model instead of sire model. The average accuracy GP for lameness was often higher in Holsteins compared with Jerseys. However, using multivariate sire models, the average accuracy of GP was similar in Holstein and Jersey for "sires" (0.43) and "relatives" (0.33) groups.

The average and the distribution of the accuracy GP for Holstein and Jersey sires with different number of daughters' records are shown in Figure 6. The number of sires with $<10,10-49,50-99,100-499$, and $\geq 500$ daughters' records in Holstein (and Jersey) were 5,252, 


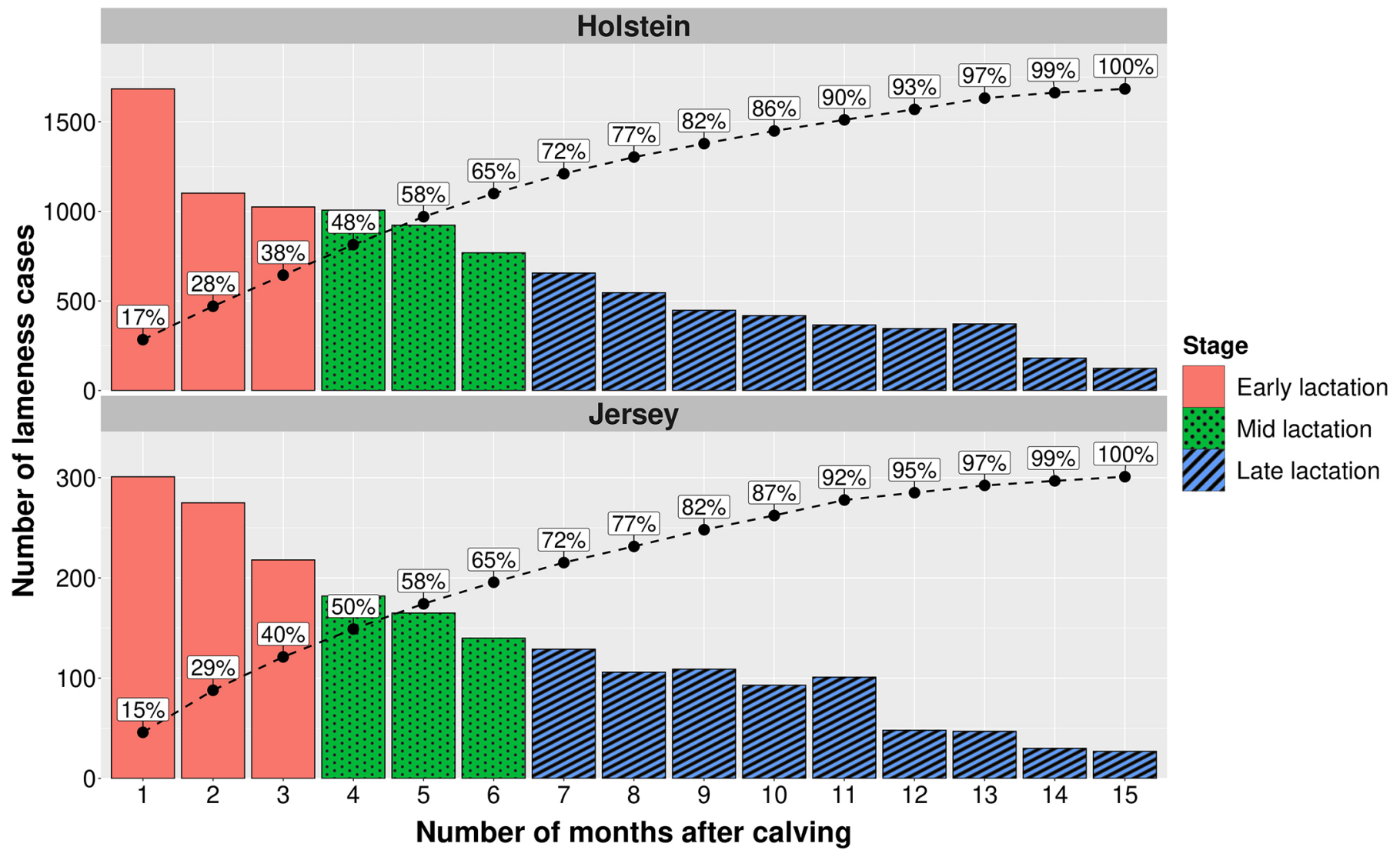

Figure 4. Distribution of lameness incidences in months after calving in Holstein and Jersey cows. As cumulative percentages of lameness cases across lactation are shown, $38 \%$ and $40 \%$ of lameness cases were recorded in early lactation stage in Holstein and Jersey cows, respectively.

$2,618,283,277$, and 71 (and 1,009, 378, 71, 52, and 12), respectively. Generally, as expected the accuracy of GP for lameness increased with the number of daughters' records. Further, using multivariate models could sufficiently increase the accuracy of GP for lameness in Jersey sires to an equivalent level as Holstein sires.

\section{DISCUSSION}

\section{Lameness Incidence Rate}

Lameness is a prevalent multifactorial disease that has large negative effects on animal welfare and the economic performance of cows (Cha et al., 2010; van der Linde et al., 2010). However, it is under-recorded in Australian dairy farms (Beggs et al., 2019). Consequently, the lameness rate in our study was lower than the reported 12 to $19 \%$ unsound cows (i.e., nonzero score) by lameness scoring of grazing herds (Haskell et al., 2006; Ranjbar et al., 2016; Bonfatti et al., 2020). This under-recording was expected because on average farmers could only identify about a quarter of lameness cases in pasture-based dairy herds (Ranjbar et al., 2016; Beggs et al., 2019). Beggs et al. (2019) reported the prevalence of lame cows identified by Australian farmers across herds ranged between 0 and $11.4 \%$ (mean 3.8\%)

Table 1. The estimated heritability $\left(\mathrm{h}^{2}\right) \pm \mathrm{SE}$ and repeatability $\left(\mathrm{r}^{2}\right) \pm \mathrm{SE}$ for lameness in Holstein and Jersey breeds in univariate models

\begin{tabular}{|c|c|c|c|c|}
\hline Model (distribution) & \multicolumn{2}{|c|}{ Holstein } & \multicolumn{2}{|c|}{ Jersey } \\
\hline Univariate sire model (binomial) & $0.050 \pm 0.012$ & $0.129 \pm 0.014$ & $0.037 \pm 0.024$ & $0.115 \pm 0.028$ \\
\hline Univariate sire model (normal) & $0.007 \pm 0.002$ & $0.029 \pm 0.002$ & $0.005 \pm 0.003$ & $0.027 \pm 0.006$ \\
\hline Univariate animal model (normal) & $0.006 \pm 0.001$ & $0.024 \pm 0.002$ & $0.009 \pm 0.004$ & $0.029 \pm 0.006$ \\
\hline
\end{tabular}




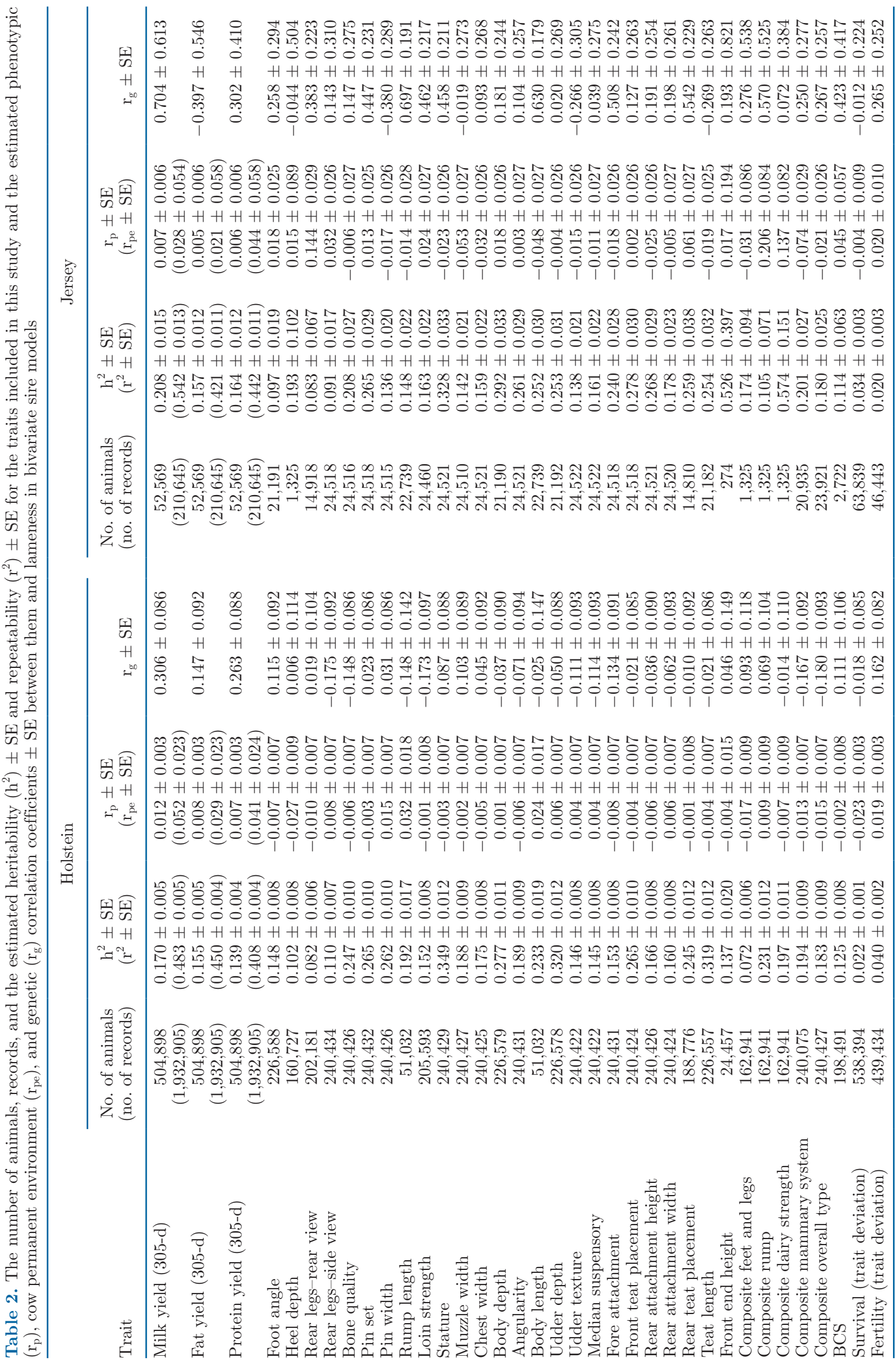


Table 3. The estimated heritability $\pm \mathrm{SE}$ (diagonal) of the traits and the genetic correlation $\pm \mathrm{SE}$ (upper triangular) and phenotypic correlation (lower triangular) $\pm \mathrm{SE}$ between them in a multivariate model used to improve prediction accuracy for lameness in the Holstein breed

\begin{tabular}{lcccc}
\hline Trait & Lameness & Milk yield (305-d) & Composite overall type & Fertility (trait deviation) \\
\hline Lameness & $\mathbf{0 . 0 0 8} \pm \mathbf{0 . 0 0 2}$ & $0.284 \pm 0.078$ & $-0.062 \pm 0.094$ & $0.230 \pm 0.083$ \\
Milk yield (305-d) & $0.011 \pm 0.003$ & $\mathbf{0 . 1 6 7} \pm \mathbf{0 . 0 0 5}$ & $0.335 \pm 0.028$ & $0.612 \pm 0.018$ \\
Composite overall type & $-0.015 \pm 0.007$ & $0.058 \pm 0.008$ & $\mathbf{0 . 1 8 2} \pm \mathbf{0 . 0 0 9}$ & $0.297 \pm 0.032$ \\
Fertility (trait deviation) & $0.019 \pm 0.003$ & $0.110 \pm 0.004$ & $0.031 \pm 0.003$ & $\mathbf{0 . 1 5 7} \pm \mathbf{0 . 0 0 6}$ \\
\hline
\end{tabular}

and Abdelsayed et al. (2017) reported the lameness rate in Australia across lactations ranged between 1.5 and $3.1 \%$ (mean $2 \%$ ). These results matched with ours showing the underestimated lameness prevalence rate in Australian dairy farms. However, the most serious cases were expected to be diagnosed by farmers, which made the recorded cases at farms potentially valuable for genetic evaluations (Abdelsayed et al., 2017).

In our study, the lameness incidence rate was higher in Jerseys (4.6\%) compared with Holsteins (3.3\%). This could be due to more complete recording of lameness in Jersey herds and does not necessarily mean that Jersey cows have higher susceptibility than Holstein cows. In fact, the Jersey breed has been shown to be more tolerant to hoof and claw diseases compared with Holsteins, which is often reported as the breed most susceptible to lameness (Barański et al., 2008; Barker et al., 2010).

The number of recorded cases of lameness in our data set was lower than studies that classified lameness into several types (Heringstad et al., 2018). For this reason, we combined the data of multiple types of lameness to have a reasonable number of cases for GP. Furthermore, it was not possible to identify the reason for $27 \%$ of the cases recorded, as lameness-related treatments. For example, a "lameness treatment" record in our data set could be associated with a footrot, or any other infectious lameness case, which was treated using antibiotics. Interestingly, the ratio of the number of "lameness treatments" on "footrot cases" showed an increasing trend in recent years, which was expected because the veterinarians were progressively urged to keep records of all treatments with antibiotics at farms.

Although the incidence rate of lameness in our study was low, the variation in number of cases across years matched well with the average amount of annual rainfall. Hence, for example, the number of recorded lameness cases in 2015 (a dry year) was almost half of 2016 (a wet year; BOM, 2020). This is in agreement with previous reports that variation in the incidence of lameness across years in pasture-based dairy herds can be explained by differences in rainfall and other environmental factors (Williams et al., 1986; Ranjbar et al., 2016). Further, within a year, there were more recorded cases of lameness from July to September inclusive. The previous studies also found up to $5 \%$ higher incidence rate of lameness in winter and early spring compared with summer (Clarkson et al., 1996; Rutherford et al., 2009). Generally, the excessive moisture at pasture may soften the claw horn and increase the susceptibility to injuries and infections which could cause lameness (Vermunt and Greenough, 1995; Borderas et al., 2004).

The higher rate of lameness between July and September overlaps with the spring calving season in Australia. Therefore, in addition to the negative effect of wet pasture on hoof health, the transition from the nonproductive to lactating phase and stressful early lactation stage may also contribute to the observed higher rate of lameness in winter and early spring. Green et al. (2002) reported higher rates of lameness in early lactation, especially in the second and third months after calving. They also described higher levels of milk production, peaking in early lactation, as a risk factor for lameness. The other contributing factor in grazing dairy herds could be that in the weeks before calving cows are often on pasture and walking very little. However, after calving, cows need to quickly adapt to walking longer distances (to and from the milking parlor) and standing on hard floors waiting for and during milking, which could adversely affect their hoof health (Somers et al., 2005).

Table 4. The estimated heritability \pm SE (diagonal) of the traits and the genetic correlation \pm SE (upper triangle) and phenotypic correlation (lower triangle) $\pm \mathrm{SE}$ between them in a multivariate model used to improve prediction accuracy for lameness in the Jersey breed

\begin{tabular}{lccccc}
\hline Trait & Lameness & Milk yield (305-d) & Stature & Body length & Fertility (trait deviation) \\
\hline Lameness & $\mathbf{0 . 0 0 8} \pm \mathbf{0 . 0 0 4}$ & $0.362 \pm 0.172$ & $0.374 \pm 0.203$ & $0.475 \pm 0.197$ & $0.278 \pm 0.213$ \\
Milk yield (305-d) & $0.007 \pm 0.006$ & $\mathbf{0 . 2 1 1} \pm \mathbf{0 . 0 1 5}$ & $0.350 \pm 0.061$ & $0.419 \pm 0.061$ & $0.316 \pm 0.068$ \\
Stature & $-0.025 \pm 0.027$ & $0.095 \pm 0.023$ & $\mathbf{0 . 3 4 4} \pm \mathbf{0 . 0 3 3}$ & $0.939 \pm 0.017$ & $0.003 \pm 0.090$ \\
Body length & $-0.036 \pm 0.027$ & $0.127 \pm 0.023$ & $0.618 \pm 0.005$ & $\mathbf{0 . 2 6 1} \pm \mathbf{0 . 0 2 8}$ & $-0.039 \pm 0.094$ \\
Fertility (trait deviation) & $0.019 \pm 0.010$ & $0.063 \pm 0.010$ & $0.015 \pm 0.008$ & $0.006 \pm 0.008$ & $\mathbf{0 . 0 8 3} \pm \mathbf{0 . 0 1 1}$ \\
\hline
\end{tabular}


As a consequence of longer calving intervals in lame cows, there were more late spring calvings (September and October) in lame compared with nonlame cows. Walker et al. (2008) reported in a grazing herd with year-round calving, that lame cows displayed weaker estrus behavior as they spend more time lying and this could impair their fertility. Generally, lameness has a detrimental effect on fertility and in a seasonal breeding pasture-based system, it was estimated that on average the open days increased by $12 \mathrm{~d}$ in lame cows (Alawneh et al., 2011).

\section{Heritability and Repeatability of Lameness}

The estimated $h^{2}$ and $r^{2}$ were higher in the threshold models compared with linear models because threshold models assume that there was underlying distribution of liability to be lame compared with raw scale $(0$ and 1$)$ observational variance in the linear models. This could reduce the residual variance in our threshold models and consequently increase the estimated $\mathrm{h}^{2}$, which is in agreement with previous reports (König et al., 2008; Heringstad et al., 2018). Further, including auxiliary traits in our multivariate models marginally increased the $\mathrm{h}^{2}$, especially for Jerseys, which had fewer number of records compared with Holstein. The previous studies also reported increased $\mathrm{h}^{2}$ for lameness by including the traits highly correlated with difficulty moving, such as claw and locomotion scores to the prediction model (Green et al., 2002; Heringstad et al., 2018).

The lameness incidence rate was very low in our study, otherwise we could potentially improve the estimation of genetic components of this trait by analyzing the cases based on the underlying reasons, or grouping the cases to infectious and noninfectious categories (Heringstad et al., 2018). Dhakal et al. (2015) reported $\mathrm{a} \mathrm{h}^{2}$ of $0.04 \pm 0.01$ for lameness in a pedigree-based threshold model, which was close to our estimates. However, by classifying the cases according to types of lameness, the $\mathrm{h}^{2}$ was increased to $0.11 \pm 0.05$ and $0.10 \pm 0.05$ for infectious and noninfectious lameness, respectively. Laursen et al. (2009) also reported a $\mathrm{h}^{2}$ of

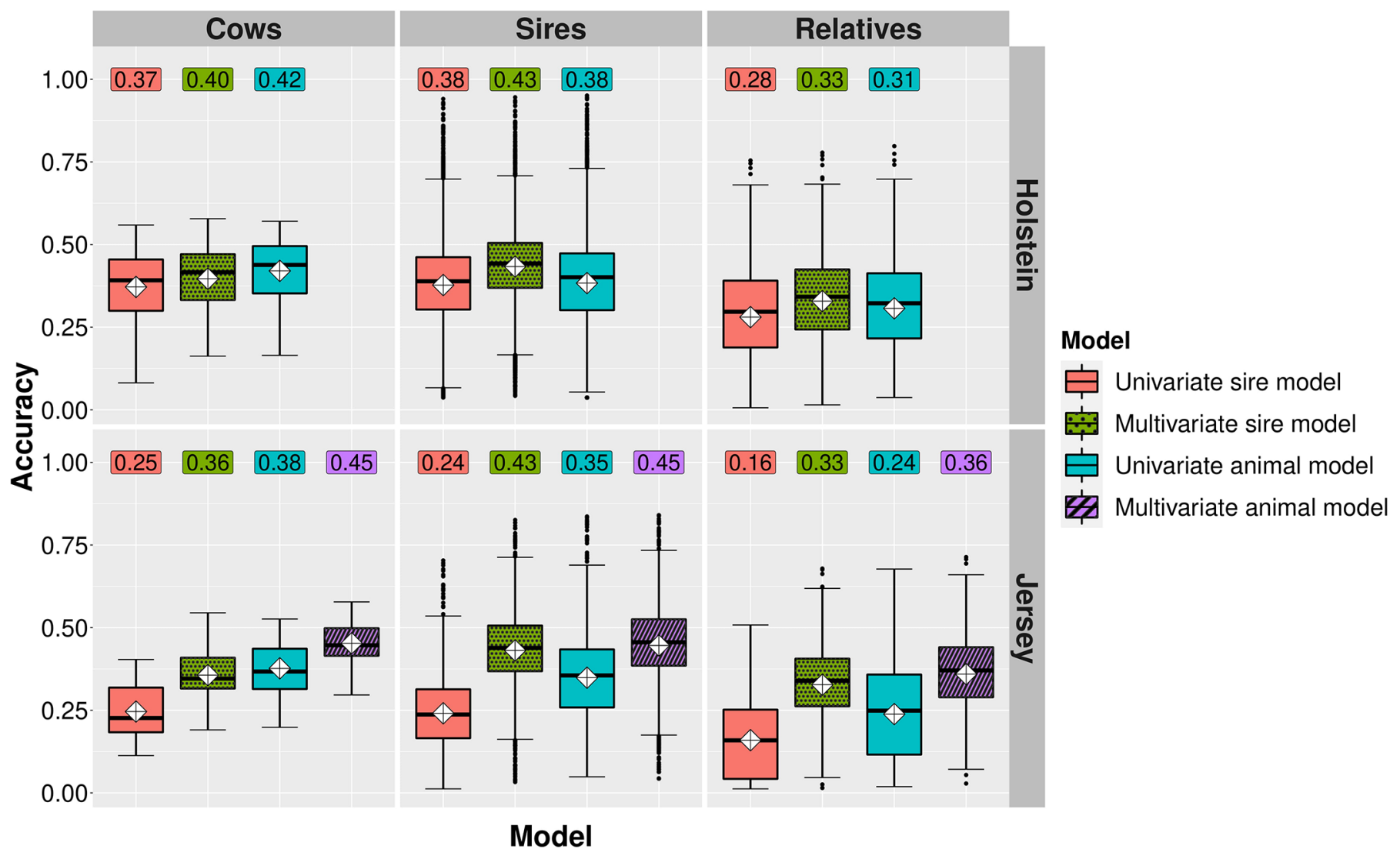

Figure 5. Accuracy of lameness predictions in Holstein and Jersey breeds using univariate and multivariate sire or animal models. The accuracies were shown for the cows or the cohort of the cows with lameness records, their sires, and the rest of relatives in the pedigree. The average accuracy of predictions for each group is given at the top of the boxplot. In the boxplots, the boxes show the middle $50 \%$ or interquartile range (i.e., the range between the first and third quartiles), the whiskers represent the data outside the middle $50 \%$ (i.e., the lower and upper $25 \%$, outlier exclusive), the diamond marks show the average, and the horizontal lines in the boxes denote the median of the data. 


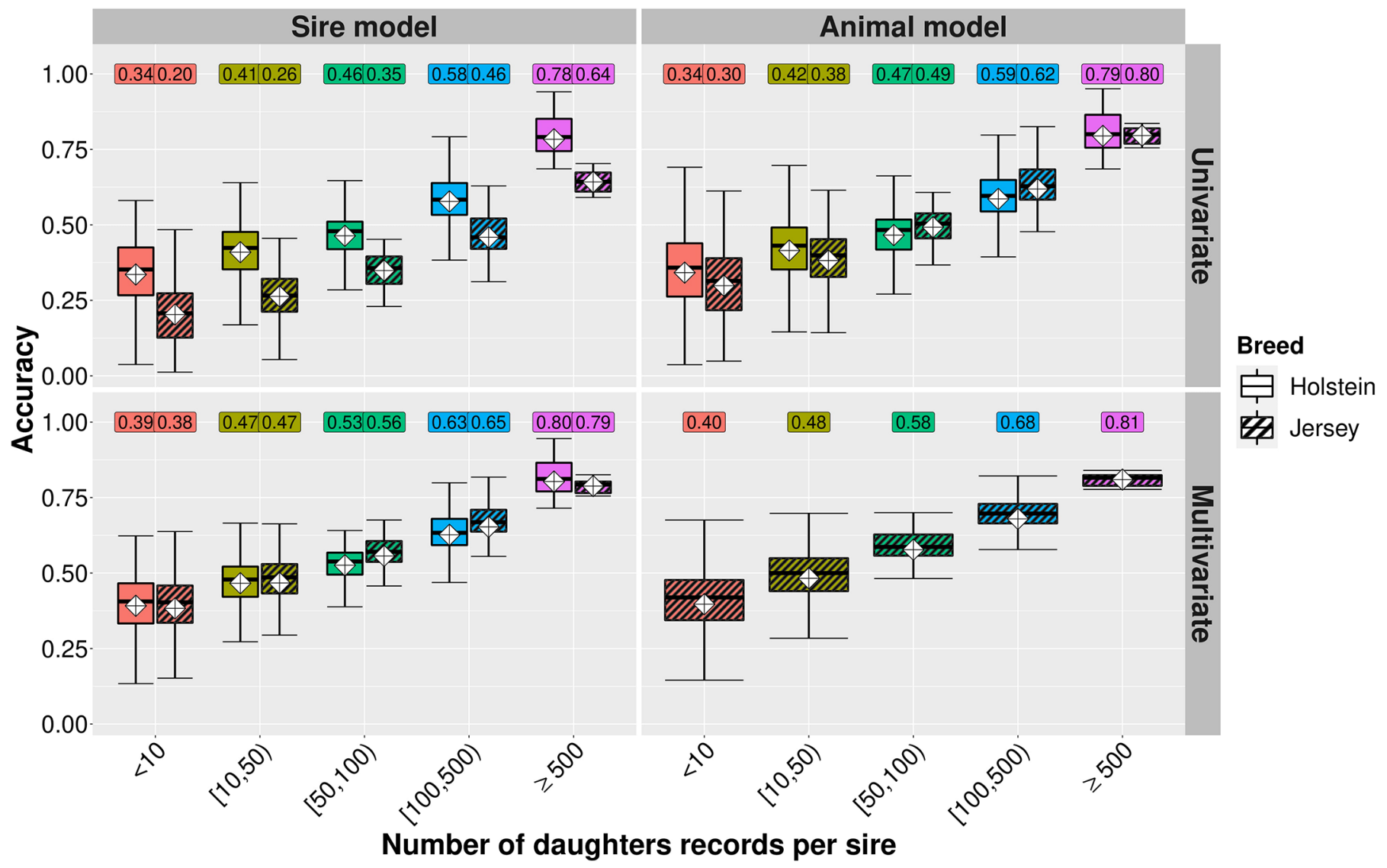

Figure 6. Accuracy of lameness predictions for Holstein and Jersey sires with different number of daughters that have lameness records or their cohorts. Increasing the number of daughters' records and using multivariate models could increase the accuracy of prediction for lameness. The average accuracy of predictions for each group is given at the top of the boxplot. In the boxplots, the boxes show the middle $50 \%$ or interquartile range (i.e., the range between the first and third quartiles), the whiskers represent the data outside the middle $50 \%$ (i.e., the lower and upper $25 \%$, outlier exclusive), the diamond marks show the average, and the horizontal lines in the boxes denote the median of the data.

0.01 for combined claw and leg disorders, which was lower than the $\mathrm{h}^{2}$ calculated separately for claw health (0.06) and feet and leg conformation traits (ranged between 0.14 to 0.27 ).

The estimated variance for cow permanent environment effect was larger than genetic variance and consequently the estimated $r^{2}$ was much higher than $h^{2}$ in our study. Hence, lameness is a trait with some degree of repeatability across lactations and a history of cases could be used as a risk factor for reoccurrence of lameness in their future lactations.

\section{Correlation Between Lameness and Other Traits}

Selective breeding for higher milk production along with increasing the scale of production were reported to have detrimental effects on health and welfare of dairy cows (Lean et al., 2008; Berry et al., 2011; Beggs et al., 2015). However, in recent decades, the antagonistic correlations between production and some health-related traits (such as mastitis, fertility, and survival) have been considered in defining a balanced breeding objective with the aim to increase overall profitability (Berry et al., 2011). Nevertheless, without having reliable predictions for lameness to be incorporated in the selection objective like some other health traits, the prevalence of lame cows at farms could be expected to increase as a correlated response to selection for milk production.

Although high milk production was reported to be correlated with impaired locomotion and claw disorder (König et al., 2008; Abdelsayed et al., 2017), the incidence of lameness has a negative effect on milk production (Green et al., 2002; Amory et al., 2008). Green et al. (2002) explained that the reduction in milk production, especially in high yielding lame cows, could be less obvious in the 305-d milk yield, because lameness incidences often reduces just a small proportion of overall production (1.4-4.7\% in pasture-based system according to O'Connor et al., 2020b). This should be considered when assessing the economic cost due to 
milk losses, despite the positive $r_{p}$ and $r_{g}$ between milk traits and lameness we found in this study. Further, we should also consider the correlations between predictor traits in explaining the association between lameness and production traits. Similarly, the correlation between milk yield and lameness may explain some unexpected correlations between some of the type traits related to mammary system and lameness. Such unexpected or hard-to-explain correlations between type traits and lameness were also observed by Abdelsayed et al. (2017).

The association between BCS and lameness should be interpreted with caution. The occurrence of lameness could reduce DMI and consequently be associated with low BCS in both intensive and pasture-based production systems (Espejo and Endres, 2007; Walker et al., 2008). Similarly, low BCS could be associated with a decreased thickness of the digital cushion, causing claw and sole noninfectious diseases and thereby lameness (Bicalho et al., 2009; Newsome et al., 2017). In contrast to the above cause-and-effect associations, excessive weight, such as high BCS, could be correlated with higher lameness prevalence (Rouha-Mülleder et al., 2009; Abdelsayed et al., 2017). Interestingly, in Jerseys we found a positive correlation between body size (stature and body length) and lameness. However, the greater body size in Jersey cows may also be because of crossing with Holstein breed, known to be more susceptible to lameness. In our study, BCS was measured at the time of classification for type traits and as the genetic correlation was similar in size to its standard error, it was expected to have very limited use as a predictor for lameness and therefore was not included in our multivariate models.

In previous studies, lameness has been reported to be associated with poor fertility, such as longer open days and calving interval and delayed ovarian activity after calving (Garbarino et al., 2004; Hultgren et al., 2004; Alawneh et al., 2011). Although locomotion problems were associated with reduced fertility in both housed and pasture-based systems, it could affect culling decisions in pasture-based herds with seasonal breeding program to a greater extent, as cows that do not calve in time are likely to be culled due to poor fertility (Alawneh et al., 2011). We found an unfavorable relationship between lameness and fertility (i.e., longer calving interval), which was also reported in spring-calving pasture-based production systems (Abdelsayed et al., 2017; O'Connor et al., 2020b). Although the previous studies suggested that lameness could cause poor fertility, the factors impairing both locomotion and fertility, such as metabolic disorders (e.g., ruminal acidosis and ketosis), could also partly explain the observed associa- tion between these traits (Lean et al., 2008; Heringstad et al., 2009; Bruijnis et al., 2010). Moreover, the strong correlations between fertility and other traits such as production and rump traits may also lead to an adverse relationship between lameness and fertility.

Lameness incidences could be directly (culling due to acute case), or indirectly (culling due to drop in milk yield or infertility) associated with reduced survival (Bicalho et al., 2007). Lameness is one of the major direct reasons for involuntary culling and the lame cows were reported to be 1.5 to 8.4 times more likely to be culled compared with their nonlame herd contemporaries (Huxley, 2013). The variation in the risk of culling because of lameness could be associated with the acuteness and underlying reason of the disease, as well as production level and pregnancy status of the cows and thereby reported to be higher in early lactation stage and increased lactation number (Booth et al., 2004; Huxley, 2013). In our study, the correlation between lameness and survival was, as expected, in a negative direction, but was very small, which could be due to under-recording of lameness cases associated with culling at farms. This could happen as some of the old, or acutely lame cows may have received no treatment before culling, or there could be multiple reasons to cull those lame cows. For example, fertility problems, instead of lameness, might be considered (and recorded) as the exit reason for a nonpregnant lame cow that was culled from the herd. Hence, some of the lameness incidences leading to culling of the cows could be recorded as a range of different problems that may coincide with lameness.

The conformation traits, especially the feet and leg type traits, could be associated with claw health and locomotion score (Onyiro and Brotherstone, 2008; van der Linde et al., 2010). However, estimating the correlation between type traits and lameness could be challenging because cows are normally type-classified only once after first calving and there may be nonlinear correlations between the scores and lameness (i.e., the intermediate scores might be favored for some type traits). Furthermore, extremely poor scores are rare because often only cows with the most desirable attributes are classified. Finally, type traits are mainly correlated with claw disorders and noninfectious lameness cases (van der Waaij et al., 2005; Oikonomou et al., 2013; Ring et al., 2018). Given the potential confounding effects of these limitations in our study, the estimated correlations between type traits and lameness were often low. Consequently, we just included overall type for Holstein and body length and stature for Jerseys as correlated type traits with lameness in the multivariate prediction models. 


\section{Genetic Prediction of Lameness}

Although lameness significantly affects the economic performance of dairy cows directly (costs of treatment and earlier culling) and indirectly (reduced milk production and impaired infertility), the low accuracy of GP has limited the implementation of selective breeding for improving this trait like many other health traits (Berry et al., 2011; Huxley, 2013). However, according to previous studies, the accuracy of GP for lameness could be increased by (1) improving the accuracy of phenotypes by training farmers and veterinarians (Berry et al., 2011); (2) using lameness/locomotion scores in GP of claw health or lameness (Ring et al., 2018; Köck et al., 2019); (3) adding lameness/locomotion scores and hoof trimming records as indicator traits in the prediction model (Laursen et al., 2009; van der Linde et al., 2010; Heringstad et al., 2018); (4) adding conformation traits, especially feet and leg type traits, to the model (Onyiro and Brotherstone, 2008; Laursen et al., 2009); (5) partitioning the lameness incidences to infectious and noninfectious cases (Dhakal et al., 2015; Heringstad et al., 2018); (6) partitioning the claw disorders to hygiene-related (digital dermatitis, interdigital dermatitis, and interdigital hyperplasia) and laminitis-related (sole hemorrhage, sole ulcer, and white line disease) cases (van der Linde et al., 2010); (7) considering claw and leg health as 2 correlated traits in the prediction model (Laursen et al., 2009); and (8) using genomic data in the evaluations (Dhakal et al., 2015). Further, with the use of the modern technologies such as locomotion sensors, accelerometers, mid-infrared spectroscopy, thermal imaging, and image processing, we expect it may be possible to detect and record lameness incidences more accurately and potentially on a large scale at a reasonable cost (Zhao et al., 2018; Bonfatti et al., 2020; O'Leary et al., 2020).

The estimated accuracy for lameness was very low in our univariate models, and as a practical solution to increase the accuracy of GP with the available data, we added some routinely measured auxiliary traits to the prediction model. Most of the type traits were not correlated with lameness in our study, and therefore we also included 305-d milk yield for all lactations and fertility TD in the multivariate models.

The improvement in the accuracy of GP by including auxiliary traits in sire models was limited for Holsteins ( 0.03 or $8 \%$ for cows and 0.05 or $13 \%$ for sires) compared with Jersey ( 0.11 or $44 \%$ for cows and 0.19 or $79 \%$ for sires). Hence, the multivariate models outperformed the univariate models, especially when the number of lameness records was limited, as in the Jersey breed. Further, comparing the accuracy of GP for the sires with different number of daughters' records, we found large differences between the accuracy of prediction of Holstein and Jersey sires in univariate models, but the gap disappeared in multivariate models. This also confirmed the usefulness of including auxiliary traits in the prediction models when a limited number of lameness records was available. However, to achieve an accuracy of 0.80 in sires, $>500$ daughters' records (lame and nonlame) was required, which could be only achieved for 71 Holstein and 12 Jersey sires. Laursen et al. (2009) also reported the accuracy of GP for claw health improved by including locomotion score and rear legs-rear view to the model and was 0.25 (and 0.54) for the sires with 10 (and 100) daughters' records. Nevertheless, to assess the actual improvement in accuracy due to using predictor traits, we strongly recommend testing our multivariate models in an independent validation set, which has quality lameness records.

Heringstad et al. (2018) in their review paper emphasized the need for a large number of high-quality phenotypes and including auxiliary traits in the prediction models for having robust genetic evaluations for claw health as a proxy of lameness. Further, they mentioned the lack of sires with reliable genomic EBV for claw health could limit the application of genomic selection for claw disorders and locomotion problems. Hence, genetic gain for reduced mobility problems is possible but challenging, because it requires a large number of records.

\section{CONCLUSIONS}

The identification of lame cows on farms is often limited to only acute cases. Consequently, moderately lame cases are probably not always diagnosed and in most cases are ignored until they develop into severe cases. This reactive approach creates an unrealistically low frequency of lameness and could increase the economic loss due to delayed treatments as well. We found in this study that under-recording of the lameness incidences on Australian farms resulted in very low $\mathrm{h}^{2}$ and low accuracy of GP. Including some conformation traits, 305-d milk yield, and fertility as auxiliary traits to the prediction models moderately increased the accuracies, especially for the Jersey breed. However, the accuracy of GP for most of the cows and sires still needs to be improved before reaching an acceptable level. A proactive approach to distinguish lameness at early stages through continuous monitoring of locomotion and recording the underlying reasons of the difficulty moving for all cases could be beneficial from a management perspective to reduce the economic loss as well as assembling large high-quality data set, which is crucial to quantify the actual prevalence rate and improving the accuracy of GP for lameness. 


\section{ACKNOWLEDGMENTS}

The authors declare that there is no conflict of interest in relation to this study and acknowledge financial support from DairyBio, a joint venture of Dairy Australia, The Gardiner Foundation, and Agriculture Victoria (Melbourne, Australia). We gratefully thank DataGene, especially Gert Nieuwhof and Paul Koh, the herd-test organizations, and the farmers for providing the data for our research.

\section{REFERENCES}

Abdelsayed, M., M. Haile-Mariam, and J. E. Pryce. 2017. Genetic parameters for health traits using data collected from genomic information nucleus herds. J. Dairy Sci. 100:9643-9655. https:// doi.org/10.3168/jds.2017-12960.

Alawneh, J. I., R. A. Laven, and M. A. Stevenson. 2011. The effect of lameness on the fertility of dairy cattle in a seasonally breeding pasture-based system. J. Dairy Sci. 94:5487-5493. https://doi.org/ 10.3168/jds.2011-4395.

Amory, J. R., Z. E. Barker, J. L. Wright, S. A. Mason, R. W. Blowey, and L. E. Green. 2008. Associations between sole ulcer, white line disease and digital dermatitis and the milk yield of 1824 dairy cows on 30 dairy cow farms in England and Wales from February 2003-November 2004. Prev. Vet. Med. 83:381-391. https://doi .org/10.1016/j.prevetmed.2007.09.007.

Barański, W., T. Janowski, and S. Zduńczyk. 2008. Incidence of reproduction disorders, clinical mastitis and lameness in cross-breed HF $\mathrm{x}$ BW cows and Jersey cows maintained in the same conditions. Med. Weter. 64:1201-1204.

Barker, Z. E., K. A. Leach, H. R. Whay, N. J. Bell, and D. C. J. Main. 2010. Assessment of lameness prevalence and associated risk factors in dairy herds in England and Wales. J. Dairy Sci. 93:932-941. https://doi.org/10.3168/jds.2009-2309.

Beggs, D. S., A. D. Fisher, E. C. Jongman, and P. H. Hemsworth. 2015. A survey of Australian dairy farmers to investigate animal welfare risks associated with increasing scale of production. J. Dairy Sci. 98:5330-5338. https://doi.org/10.3168/jds.2014-9239.

Beggs, D. S., E. C. Jongman, P. H. Hemsworth, and A. D. Fisher. 2019. Lame cows on Australian dairy farms: A comparison of farmer-identified lameness and formal lameness scoring, and the position of lame cows within the milking order. J. Dairy Sci. 102:1522-1529. https://doi.org/10.3168/jds.2018-14847.

Berry, D. P., M. L. Bermingham, M. Good, and S. J. More. 2011. Genetics of animal health and disease in cattle. Ir. Vet. J. 64:5. https: //doi.org/10.1186/2046-0481-64-5.

Bicalho, R. C., V. S. Machado, and L. S. Caixeta. 2009. Lameness in dairy cattle: A debilitating disease or a disease of debilitated cattle? A cross-sectional study of lameness prevalence and thickness of the digital cushion. J. Dairy Sci. 92:3175-3184. https://doi .org/10.3168/jds.2008-1827.

Bicalho, R. C., F. Vokey, H. N. Erb, and C. L. Guard. 2007. Visual locomotion scoring in the first seventy days in milk: Impact on pregnancy and survival. J. Dairy Sci. 90:4586-4591. https://doi .org/10.3168/jds.2007-0297.

BOM. 2020. 120 years of Australian rainfall. Accessed Oct. 15, 2020. http://www.bom.gov.au/climate/history/rainfall/.

Bonfatti, V., P. N. Ho, and J. E. Pryce. 2020. Usefulness of milk mid-infrared spectroscopy for predicting lameness score in dairy cows. J. Dairy Sci. 103:2534-2544. https://doi.org/10.3168/jds .2019-17551.

Booth, C. J., L. D. Warnick, Y. T. Gröhn, D. O. Maizon, C. L. Guard, and D. Janssen. 2004. Effect of lameness on culling in dairy cows. J. Dairy Sci. 87:4115-4122. https://doi.org/10.3168/jds.S0022 -0302(04)73554-7.

Borderas, T. F., B. Pawluczuk, A. M. de Passillé, and J. Rushen. 2004. Claw hardness of dairy cows: Relationship to water content and claw lesions. J. Dairy Sci. 87:2085-2093. https://doi.org/10.3168/ jds.S0022-0302(04)70026-0.

Bruijnis, M. R. N., H. Hogeveen, and E. N. Stassen. 2010. Assessing economic consequences of foot disorders in dairy cattle using a dynamic stochastic simulation model. J. Dairy Sci. 93:2419-2432. https://doi.org/10.3168/jds.2009-2721.

Buch, L. H., A. C. Sørensen, J. Lassen, P. Berg, J. Å. Eriksson, J. H. Jakobsen, and M. K. Sørensen. 2011. Hygiene-related and feedrelated hoof diseases show different patterns of genetic correlations to clinical mastitis and female fertility. J. Dairy Sci. 94:1540-1551. https://doi.org/10.3168/jds.2010-3137.

Cha, E., J. A. Hertl, D. Bar, and Y. T. Gröhn. 2010. The cost of different types of lameness in dairy cows calculated by dynamic programming. Prev. Vet. Med. 97:1-8. https://doi.org/10.1016/j .prevetmed.2010.07.011.

Clarkson, M. J., D. Y. Downham, W. B. Faull, J. W. Hughes, F. J. Manson, J. B. Merritt, R. D. Murray, W. B. Russell, J. E. Sutherst, and W. R. Ward. 1996. Incidence and prevalence of lameness in dairy cattle. Vet. Rec. 138:563-567. https://doi.org/ $10.1136 / v r .138 .23 .563$

Dhakal, K., F. Tiezzi, J. S. Clay, and C. Maltecca. 2015. Short communication: Genomic selection for hoof lesions in first-parity US Holsteins. J. Dairy Sci. 98:3502-3507. https://doi.org/10.3168/jds .2014-8830.

Espejo, L. A., and M. I. Endres. 2007. Herd-level risk factors for lameness in high-producing Holstein cows housed in freestall barns. J. Dairy Sci. 90:306-314. https://doi.org/10.3168/jds.S0022 -0302(07)72631-0.

Ettema, J. F., and S. Østergaard. 2006. Economic decision making on prevention and control of clinical lameness in Danish dairy herds. Livest. Sci. 102:92-106. https://doi.org/10.1016/j.livprodsci.2005 .11 .021 .

Garbarino, E. J., J. A. Hernandez, J. K. Shearer, C. A. Risco, and W. W. Thatcher. 2004. Effect of lameness on ovarian activity in postpartum Holstein cows. J. Dairy Sci. 87:4123-4131. https://doi .org/10.3168/jds.S0022-0302(04)73555-9.

Gilmour, A. R., B. J. Gogel, B. R. Cullis, S. Welham, and R. Thompson. 2015. ASReml user guide release 4.1 structural specification. VSN International Ltd. www.vsni.co.uk.

Green, L. E., V. J. Hedges, Y. H. Schukken, R. W. Blowey, and A. J. Packington. 2002. The impact of clinical lameness on the milk yield of dairy cows. J. Dairy Sci. 85:2250-2256. https://doi.org/10 .3168/jds.S0022-0302(02)74304-X.

Haile-Mariam, M., and M. E. Goddard. 2010. Preliminary genetic analyses of voluntarily supplied disease data in Australian dairy herds. Anim. Prod. Sci. 50:186-192. https://doi.org/10.1071/ AN09113.

Haile-Mariam, M., J. Pryce, C. Schrooten, and B. Hayes. 2015. Including overseas performance information in genomic evaluations of Australian dairy cattle. J. Dairy Sci. 98:3443-3459. https://doi .org/10.3168/jds.2014-8785.

Haskell, M. J., L. J. Rennie, V. A. Bowell, M. J. Bell, and A. B. Lawrence. 2006. Housing system, milk production, and zero-grazing effects on lameness and leg injury in dairy cows. J. Dairy Sci. 89:4259-4266. https://doi.org/10.3168/jds.S0022-0302(06)72472 -9 .

Heringstad, B., C. Egger-Danner, N. Charfeddine, J. E. Pryce, K. F. Stock, J. Kofler, A. M. Sogstad, M. Holzhauer, A. Fiedler, K. Müller, P. Nielsen, G. Thomas, N. Gengler, G. de Jong, C. Ødegård, F. Malchiodi, F. Miglior, M. Alsaaod, and J. B. Cole. 2018. Invited review: Genetics and claw health: Opportunities to enhance claw health by genetic selection. J. Dairy Sci. 101:4801-4821. https:// doi.org/10.3168/jds.2017-13531.

Heringstad, B., X. L. Wu, and D. Gianola. 2009. Inferring relationships between health and fertility in Norwegian Red cows using recursive models. J. Dairy Sci. 92:1778-1784. https://doi.org/10 $.3168 /$ jds.2008-1535.

Hultgren, J., T. Manske, and C. Bergsten. 2004. Associations of sole ulcer at claw trimming with reproductive performance, udder health, milk yield, and culling in Swedish dairy cattle. Prev. Vet. 
Med. 62:233-251. https://doi.org/10.1016/j.prevetmed.2004.01 .002 .

Huxley, J. N. 2013. Impact of lameness and claw lesions in cows on health and production. Livest. Sci. 156:64-70. https://doi.org/10 .1016/j.livsci.2013.06.012.

Köck, A., B. Fuerst-Waltl, J. Kofler, J. Burgstaller, F. Steininger, C. Fuerst, and C. Egger-Danner. 2019. Short communication: Use of lameness scoring to genetically improve claw health in Austrian Fleckvieh, Brown Swiss, and Holstein cattle. J. Dairy Sci. 102:1397-1401. https://doi.org/10.3168/jds.2018-15287.

König, S., X. L. Wu, D. Gianola, B. Heringstad, and H. Simianer. 2008. Exploration of relationships between claw disorders and milk yield in Holstein cows via recursive linear and threshold models. J. Dairy Sci. 91:395-406. https://doi.org/10.3168/jds.2007-0170.

Laursen, M. V., D. Boelling, and T. Mark. 2009. Genetic parameters for claw and leg health, foot and leg conformation, and locomotion in Danish Holsteins. J. Dairy Sci. 92:1770-1777. https://doi.org/ $10.3168 /$ jds.2008-1388.

Lawson, L. G., J. F. Agger, M. Lund, and T. Coelli. 2004. Lameness, metabolic and digestive disorders, and technical efficiency in Danish dairy herds: A stochastic frontier production function approach. Livest. Prod. Sci. 91:157-172. https://doi.org/10.1016/ j.livprodsci.2004.07.016.

Lean, I.., C. T. Westwood, and M. C. Playford. 2008. Livestock disease threats associated with intensification of pastoral dairy farming. N. Z. Vet. J. 56:261-269. https://doi.org/10.1080/00480169.2008 36845 .

Newsome, R. F., M. J. Green, N. J. Bell, N. J. Bollard, C. S. Mason, H. R. Whay, and J. N. Huxley. 2017. A prospective cohort study of digital cushion and corium thickness. Part 2: Does thinning of the digital cushion and corium lead to lameness and claw horn disruption lesions? J. Dairy Sci. 100:4759-4771. https://doi.org/ 10.3168/jds.2016-12013.

O'Connor, A. H., E. A. M. Bokkers, I. J. M. de Boer, H. Hogeveen, R. Sayers, N. Byrne, E. Ruelle, B. Engel, and L. Shalloo. 2020a. Cow and herd-level risk factors associated with mobility scores in pasture-based dairy cows. Prev. Vet. Med. 181:105077. https://doi .org/10.1016/j.prevetmed.2020.105077.

O'Connor, A. H., E. A. M. Bokkers, I. J. M. de Boer, H. Hogeveen, R. Sayers, N. Byrne, E. Ruelle, and L. Shalloo. 2020b. Associating mobility scores with production and reproductive performance in pasture-based dairy cows. J. Dairy Sci. 103:9238-9249. https://doi .org/10.3168/jds.2019-17103.

O'Leary, N. W., D. T. Byrne, A. H. O'Connor, and L. Shalloo. 2020. Invited review: Cattle lameness detection with accelerometers. J. Dairy Sci. 103:3895-3911. https://doi.org/10.3168/jds.2019-17123.

Oikonomou, G., N. B. Cook, and R. C. Bicalho. 2013. Sire predicted transmitting ability for conformation and yield traits and previous lactation incidence of foot lesions as risk factors for the incidence of foot lesions in Holstein cows. J. Dairy Sci. 96:3713-3722. https: //doi.org/10.3168/jds.2012-6308.

Onyiro, O. M., and S. Brotherstone. 2008. Genetic analysis of locomotion and associated conformation traits of Holstein-Friesian dairy cows managed in different housing systems. J. Dairy Sci. 91:322328. https://doi.org/10.3168/jds.2007-0514.

Ranjbar, S., A. R. Rabiee, A. Gunn, and J. K. House. 2016. Identifying risk factors associated with lameness in pasture-based dairy herds. J. Dairy Sci. 99:7495-7505. https://doi.org/10.3168/jds .2016-11142.

Ring, S. C., A. J. Twomey, N. Byrne, M. M. Kelleher, T. Pabiou, M. L. Doherty, and D. P. Berry. 2018. Genetic selection for hoof health traits and cow mobility scores can accelerate the rate of genetic gain in producer-scored lameness in dairy cows. J. Dairy Sci. 101:10034-10047. https://doi.org/10.3168/jds.2018-15009.

Rouha-Mülleder, C., C. Iben, E. Wagner, G. Laaha, J. Troxler, and S. Waiblinger. 2009. Relative importance of factors influencing the prevalence of lameness in Austrian cubicle loose-housed dairy cows. Prev. Vet. Med. 92:123-133. https://doi.org/10.1016/ j.prevetmed.2009.07.008.

Rutherford, K. M. D., F. M. Langford, M. C. Jack, L. Sherwood, A. B. Lawrence, and M. J. Haskell. 2009. Lameness prevalence and risk factors in organic and non-organic dairy herds in the United Kingdom. Vet. J. 180:95-105. https://doi.org/10.1016/j.tvjl.2008 .03.015.

Sales, J., and W. G. Hill. 1976. Effect of sampling errors on efficiency of selection indices. 2. Use of information on associated traits for improvement of a single important trait. Anim. Sci. 23:1-14. https: //doi.org/10.1017/S0003356100031020.

Somers, J. G. C. J., W. G. P. Schouten, K. Frankena, E. N. Noordhuizen-Stassen, and J. H. M. Metz. 2005. Development of claw traits and claw lesions in dairy cows kept on different floor systems. J. Dairy Sci. 88:110-120. https://doi.org/10.3168/jds.S0022 -0302(05)72668-0.

van der Linde, C., G. de Jong, E. P. C. Koenen, and H. Eding. 2010. Claw health index for Dutch dairy cattle based on claw trimming and conformation data. J. Dairy Sci. 93:4883-4891. https://doi .org/10.3168/jds.2010-3183.

van der Waaij, E. H., M. Holzhauer, E. Ellen, C. Kamphuis, and G. de Jong. 2005. Genetic parameters for claw disorders in Dutch dairy cattle and correlations with conformation traits. J. Dairy Sci. 88:3672-3678. https://doi.org/10.3168/jds.S0022-0302(05)73053 -8 .

Van Nuffel, A., W. Saeys, B. Sonck, J. Vangeyte, K. C. Mertens, B. De Ketelaere, and S. Van Weyenberg. 2015. Variables of gait inconsistency outperform basic gait variables in detecting mildly lame cows. Livest. Sci. 177:125-131. https://doi.org/10.1016/j .livsci.2015.04.008.

Vermunt, J. J., and P. R. Greenough. 1995. Structural characteristics of the bovine claw: Horn growth and wear, horn hardness and claw conformation. Br. Vet. J. 151:157-180. https://doi.org/10.1016/ S0007-1935(95)80007-7.

Walker, S. L., R. F. Smith, J. E. Routly, D. N. Jones, M. J. Morris, and H. Dobson. 2008. Lameness, activity time-budgets, and estrus expression in dairy cattle. J. Dairy Sci. 91:4552-4559. https://doi .org/10.3168/jds.2008-1048.

Williams, L. A., G. J. Rowlands, and A. M. Russell. 1986. Effect of wet weather on lameness in dairy cattle. Vet. Rec. 118:259-261. https: //doi.org/10.1136/vr.118.10.259.

Zhao, K., J. M. Bewley, D. He, and X. Jin. 2018. Automatic lameness detection in dairy cattle based on leg swing analysis with an image processing technique. Comput. Electron. Agric. 148:226-236. https://doi.org/10.1016/j.compag.2018.03.014.

\section{ORCIDS}

M. Khansefid (1) https://orcid.org/0000-0002-5091-7293

M. Haile-Mariam @ (ttps://orcid.org/0000-0001-5476-7475

J. E. Pryce $\odot$ https://orcid.org/0000-0002-1397-1282 